\title{
Southern Pomo syncope is metrically conditioned: Metrical opacity and stratal derivation
}

\author{
Max J. Kaplan*
}

\begin{abstract}
Southern Pomo displays a process of rhythmic vowel deletion that appears to be sensitive to a metrical structure that is incompatible with surface stress, and is thus metrically opaque. This pattern implicates a metrical reversal, which is best accounted for by re-ranking constraints at different derivational stages in Stratal OT. The first stratum defines weak positions by building structure from left to right, while the second stratum deletes vowels in those weak positions and reassigns prominence from right to left. Some prior work has asserted that stratal models of rhythmic phonotactics overgenerate, making typologically strange predictions. This literature has argued that cases like Southern Pomo should instead be analyzed in surface-oriented, parallel systems. This paper demonstrates that Southern Pomo syncope cannot be generated in parallel, nor in derivational frameworks that are more restrictive, i.e. Harmonic Serialism. This work suggests strata are necessary, with further evidence coming from phrasal and word-internal processes, and diachronic change.
\end{abstract}

Keywords. syncope; metrical phonology; metrical opacity; Stratal OT; Southern Pomo

1. Introduction. There are many well-attested phonological processes across the world's languages that may result in opaque generalizations. Metrically-conditioned syncope - narrowly defined, the deletion of vowels in metrically weak positions (McCarthy, 2008) - is one such process. These weak positions can be syllables that are unstressed because they are a dependent within a foot, i.e. dependents, or because they are unparsed, as seen in (1):
a. Weak in foot
$\left(\right.$ óg) $\rightarrow\left(\sigma_{-}\right)^{1}$
b. Unparsed
$(\sigma \sigma) \underline{\sigma} \rightarrow(\sigma \sigma)$

This common process poses a well-known problem for parallel constraint-based approaches such as classic Optimality Theory (OT, Prince \& Smolensky, 1993/2004), as deletion must be preceded by the building of the metrical structure which conditions it - insofar as the process is truly conditioned by metrical structure (Kager, 1997; Gouskova, 2003; McCarthy, 2008).

In optimality theoretic terms, transparent applications of syncope result in the constraints driving deletion being surface-satisfied. If syncope is driven by a constraint * $\breve{V}$ ("don't have weak vowels"), this is transparent in cases where unstressed vowels are deleted, and all vowels are stressed in the output. (2) shows this in Macushi Carib (Carib; northeastern South America):

\footnotetext{
${ }^{*}$ Many thanks to Ryan Bennett, Junko Itô, and the Phlunch reading group at UC Santa Cruz for their invaluable feedback. Thanks also to Gene Buckley and Alex Walker for their generosity in sharing their Pomo language knowledge and resources. With immense gratitude to Annie Burk, Elsie Allen, and Elizabeth Dollar, whose efforts to document their language made this research possible. Author: University of California, Santa Cruz (mkaplan2@ucsc.edu).

${ }^{1}$ Underlining indicates vowels in positions targeted for syncope; underscores indicate where syncope has taken place in a surface form. For legibility, I use acute and grave accents to mark primary and secondary stresses in glosses.
} 
Syncope in Macushi Carib (Kager, 1997)
a. [w_nà:.m_rí:]
b. [wà:.n_mà:.r_rí:]
/wa.na.ma.ri/
/u.wa.na.ma.ri.ri /
"mirror"
"my mirror"

In the data in (2), only stressed vowels appear. Deletion has thus applied transparently. However, syncope is opaque when the surface form shows mis- or under-application of deletion; for example, when unstressed vowels appear in the output, or if it appears that vowels in stressed (rather than unstressed) syllables have been deleted. These cases are more difficult to describe in terms of surface-oriented constraints.

Nevertheless, several such cases in the literature have been analyzed in parallel. Previous work has resolved seemingly opaque and derivational syncope patterns in classic OT using surface-oriented constraints like STRESS-TO-WEIGHT (SWP, “don't have stress on light syllables"; Prince 1990), which maximizes the wellformedness of surface feet. Gouskova (2003) demonstrates that SWP successfully generates syncope in Tonkawa (isolate, Southwest US; cf. Blumenfeld 2006). Foot-to-edge alignment constraints (i.e., "don't have intervening syllables between a word edge and foot edge") have been similarly useful in describing syncope patterns which seem motivated by minimizing unparsed material, as in Southeastern Tepehuán (UtoAztecan, northern Mexico) and Hopi (Uto-Aztecan, Arizona) (Kager, 1997; Gouskova, 2003).

The Southern Pomo (Pomo, Northern California; iso: peq), data presented here are incompatible with such accounts. In $\$ 2$, I detail the specifics of syncope in Southern Pomo and its interaction with metrical structure. $\S 3$ demonstrates how this pattern is captured using a stratal architecture, and provides further justification for strata from independent phonological processes. Following this, $\S 4$ considers alternative approaches to the pattern from parallelist perspectives and using 'multiplanar' footing, ultimately rejecting these accounts. In $\S 5$, I briefly discuss how this stratal account might reflect diachronic change, offer a promissory note on opacity and restructuring, and conclude.

\section{Southern Pomo and syncope.}

2.1. The Language. Southern Pomo is one of the seven mutually unintelligible Pomoan languages of Northern California, which were traditionally spoken in the area around Clear Lake and the Russian River Valley. The closest of these to Southern Pomo genealogically is Kashaya (Southwestern) Pomo. Southern Pomo was spoken by somewhere from two- to seven thousand people in the area between Santa Rosa and Sebastopol, north to Cloverdale at the time of European contact. Colonial enslavement, displacement and genocide of the Pomo peoples left fewer than one hundred speakers by 1900 (Walker, 2013/2020). The language is recently dormant, but there are active community revitalization efforts.

Most recorded Southern Pomo materials feature Annie Burk (1876-1962) or her daughter Elsie Allen (1899-1990), both of whom were also renowned for their basketry, or Elizabeth Dollar (1895-1971). Though there were earlier documentary efforts, the majority of linguistic description was done by Abraham Halpern, Robert Oswalt, and most recently Neil Alexander Walker.

\subsection{SYNCOPE AND METRICAL STRUCTURE. In Southern Pomo, vowels in the third and fifth} syllables of words are deleted when these syllables are non-final. Thus, four and five syllable words undergo deletion in the third syllable, and six and seven syllable words show deletion of the vowel in the fifth syllable as well. (There are few if any words of greater length.) This pattern 
can be seen below in (3): ${ }^{2}$

Southern Pomo syncope
a. [ji:.bá: $\mathrm{th}_{n}^{\mathrm{h}} \cdot$ mhuj]
/ $\int \mathrm{i}(:) \cdot \mathrm{ba} \cdot \mathrm{t}^{\mathrm{h}} \mathrm{a}-\mathrm{mhut}-\varnothing$ /
poor- RECIP- PFV
"felt sorry for each other" (W 67)
b. [?àh.tim._k'ó.tgin]
/ Pa- (h)ti- mokotf- in /
move- foot- DIR- SG.IMP
"put foot back!" (W 134)
c. [hà:.tfat._lók._ta]
/ ha(:)- tya- t- alokotf- a /
by.wing-fly-PL.ACT-DIR-EVID
"they're flying out" (W 281)
d. [Pe:.khèt._la.mé:.le]
$/ \operatorname{Pe}(:)-\mathrm{k}^{\mathrm{h}} \mathrm{e}-\mathrm{t}-$ alametf- le/
w.body-move-PL.ACT-DIR-PL.IMP
“(2) move down from above!” (W 167)

While only morphologically complex words are long enough to undergo this process, it is pervasive, affecting both lexical and functional material. Lexical morphemes can be seen undergoing syncope in reduplication (both verbal and adjectival), in noun-noun compounding, exemplified below in (4-6), and with polysyllabic verb roots, as above in (3a): ${ }^{3}$

(4) Syncope in verbal reduplication
a. [phuh.tóp_tow]
$/ \mathrm{p}^{\mathrm{h}} \mathrm{u}-(\mathrm{h})$ to-p $^{\mathrm{h}} \underline{\mathrm{u}}-(\mathrm{h})$ tow/
boil- ITER RED- PFV
"boils" (W 140)
b. [bah.k $\left.\mathrm{k}^{\mathrm{h}} \mathrm{p} \_\mathrm{k}^{\mathrm{h}} \mathrm{Ow}\right]$
/ba-(h)k $\mathrm{k}^{\mathrm{h}} \mathrm{o}-\mathrm{ba}-(\mathrm{h}) \mathrm{k}^{\mathrm{h}} \mathrm{O}-\mathrm{w} /$
by.poking-contact-ITER RED-PFV
"to give many little pokes" (W 263)

(5) Syncope in adjectival reduplication
a. [bah.t ${ }^{\text {thép_th }}$ th $^{\text {t }}$
$/ \mathrm{ba}(\mathrm{h}) \mathrm{t}^{\mathrm{t}} \mathrm{e}-\mathrm{ba}(\mathrm{h}) \mathrm{t}^{\mathrm{t}} \mathrm{e} /$
big.COLL- INT RED
"huge" (W 140)

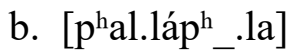
$/ p^{\text {hal }}(:) a-p^{\text {hal }}(:) \mathrm{a} /$
each-each
"various" (W 140)

(6) Syncope in noun-noun compounds
a. [?àh.k $\left.{ }^{\mathrm{h}} a p \_t a ́ . k a\right]$
/ $\mathrm{a} a(\mathrm{~h}) \mathrm{k}^{\mathrm{h}} \mathrm{a}-\mathrm{bu}(:)$ taka/
water- bear
"sea lion" (W 136)
b. [hu?.?úk ${ }^{\mathrm{h}}$ _be]
/hu(?)?uy- kha(?)be/
face- rock
"eyes" (W 179)

Syncope is regular across the lexicon, and falls on alternating syllables. However, this rhythmic process is in conflict with the language's stress system. Main stress in Southern Pomo falls on the penult, with iterating secondary stresses falling on every other syllable from right to left (McLendon, 1972; Walker, 2013/2020). That is, the surface metrical structure counts from

\footnotetext{
${ }^{2}$ All Southern Pomo examples are from Walker (2013/2020), which presents the author's fieldwork as well that of Abraham Halpern and Robert Oswalt. Examples here are annotated, e.g. "W 134" for "Walker (2013/2020), p. 134." The segments in parentheses are the so-called "laryngeal increment" (Oswalt, 1976), a feature which Southern Pomo shares with other languages in the family. This appears in all words and has the effect of making all initial syllables heavy. For discussion, see Halpern (1984) and Walker (2013, pp. 165-7), as well as Buckley (1992) and Oswalt (1998) for discussion of this phenomenon in Kashaya Pomo.

${ }^{3}$ Verbs are typically comprised of a lexical instrumental prefix and a root, together forming a lexical stem that is usually - but not always - bisyllabic.
} 
the right edge of the word. ${ }^{4}$ In morpheme strings with an odd number of syllables, syncope targets syllables which would be weak given this regular surface stress, in line with the idea that syncope targets vowels in metrically weak positions. However, in forms with underlyingly even syllable parity, it is syllables that would be in strong positions which are deleted. This is schematized in (7):

(7) Southern Pomo syncope schematized
a. Four syllables: $\quad / \sigma_{1} \sigma_{2} \underline{\sigma}_{3} \sigma_{4} /$
$\rightarrow \quad\left[\hat{\sigma}_{1} \sigma_{2-} \hat{\sigma}_{4}\right] \quad *\left[\hat{\sigma}_{1} \sigma_{2} \underline{\sigma}_{3} \sigma_{4}\right]$
b. Five syllables: $\quad / \sigma_{1} \sigma_{2} \underline{\sigma}_{3} \sigma_{4} \sigma_{5} /$
$\rightarrow \quad\left[\hat{\sigma}_{1} \sigma_{2-} \hat{\sigma}_{4} \sigma_{5}\right] \quad *\left[\sigma_{1} \hat{\sigma}_{2} \underline{\sigma}_{3} \hat{\sigma}_{4} \sigma_{5}\right]$
c. Six syllables: $\quad / \sigma_{1} \sigma_{2} \underline{\sigma}_{3} \sigma_{4} \underline{\sigma}_{5} \sigma_{6} /$
$\rightarrow \quad\left[\hat{\sigma}_{1} \sigma_{2-} \hat{\sigma}_{4-} \sigma_{6}\right] \quad *\left[\hat{\sigma}_{1} \sigma_{2} \underline{\sigma}_{3} \sigma_{4} \underline{\sigma}_{5} \sigma_{6}\right]$
d. Seven syllables: $\quad / \sigma_{1} \sigma_{2} \underline{\sigma}_{3} \sigma_{4} \underline{\sigma}_{5} \sigma_{6} \sigma_{7} l$
$\rightarrow \quad\left[\sigma_{1} \hat{\sigma}_{2-} \sigma_{4-} \sigma_{6} \sigma_{7}\right]$
$*\left[\sigma_{1} \sigma_{2} \underline{\sigma}_{3} \sigma_{4} \underline{\sigma}_{5} \sigma_{6} \sigma_{7}\right]$

Syncope in Southern Pomo thus exhibits both kinds of opacity discussed above: there is apparent underapplication, in that unstressed vowels appear on the surface, as well as misapplication, because it appears that for forms with even syllable parity, strong positions have undergone deletion. Syncope is thus not predictable based on surface metrical structure, despite its apparent regularity relative to the left word edge.

Assuming that there are not different phonological grammars for words of even and odd numbers of syllables, this non-isomorphism between stress and syncope in even-parity words suggests that stress and syncope are calculated based on two separate metrical structures which disagree in their direction of application. Syncope occurs in the weak positions defined by a leftto-right alternating count, while stress corresponds to a right-to-left alternating count. ${ }^{5}$

Syncope can be blocked by phonotactic constraints, including a ban on complex onsets and codas (i.e., *COMPLEX). This can be seen in (8):

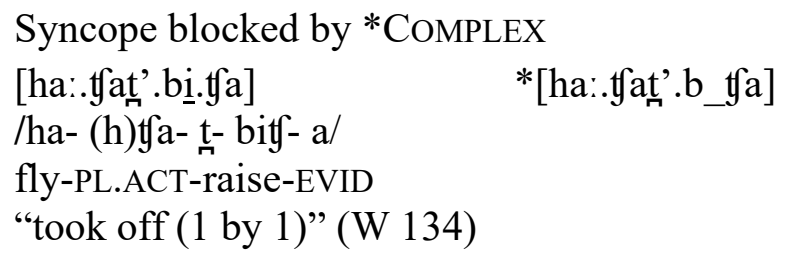

It is worth noting that the same phonotactic constraints that block syncope when it would create a complex coda or onset word-medially also prohibit deletion of the vowel in the initial syllable. All syllables in Southern Pomo surface with onsets (suggesting that this is another undominated constraint), and because of this, deletion in an initial syllable will necessarily result in an illicit onset cluster.

2.3 Derivational Metrical StRucture. The Southern Pomo data suggests a derivational account, with these conflicting structures existing at sequential stages. Such an account must provide the grammar with the means to accomplish three tasks. First, metrical structure must be built from left to right, properly assigning prominence to only those syllables which are not

\footnotetext{
${ }^{4}$ This has been characterized as a trochaic system (Buckley, 2019). While compatible with a representation using feet of either type, the present analysis requires neither and is ultimately agnostic on this point, instead utilizing an unbracketed grid approach (Prince, 1983).

${ }^{5}$ This has been characterized as a trochaic system (Buckley, 2019). While compatible with a representation using feet of either type, the present analysis requires neither and is ultimately agnostic on this point, instead utilizing an unbracketed grid approach (Prince, 1983).
} 
targeted for deletion in the output. Next, the weak positions must undergo syncope. Finally, metrical structure must be assigned from right to left, generating the observed surface stress.

3. A stratal analysis. Because syncope is dependent on the existence of metrical structure, the first stratum must be responsible for assigning the prominences which then condition rhythmic vowel deletion. The second stratum is then able to reference existing structure, and because of this it can accomplish both syncope and stress realignment in parallel. The surface regularity of rhythmic stress suggests that *CLASH ("don't have consecutive stressed syllables") and *LAPSE ("don't have consecutive unstressed syllables") are undominated throughout (Gordon, 2002).

3.1. StRATUM I. Assuming a ranking of MAX-V over $* V$ in this stratum guarantees that metrical syncope does not occur at this stage. To define the correct weak positions that syncope acts on in the second stratum, the essential ranking is that between two TROUGH constraints:

(9) TROUGH- $\{$ LEFT/RIGHT $\}$ : Assign one violation just in case there is a prominence at the $\{$ left/right $\}$ edge of the word.

In the first stratum, TROUGH-L dominates TROUGH-R, which has the effect of assigning stress from left to right. Tableau 1 and 2 demonstrate that this ranking generates the correct structure for even and odd parity forms, where the targeted syllable is in a weak position.

\begin{tabular}{|ll||c|c|}
\hline & $\sigma \sigma \underline{\sigma} \sigma$ & TROUGH-L & TROUGH-R \\
\hline \hline a. & $\sigma \sigma \sigma o \sigma o \sigma$ & & $*$ \\
\hline b. & $\sigma \sigma \sigma o ́ \sigma$ & $* ! \mathrm{W}$ & $\mathrm{L}$ \\
\hline
\end{tabular}

Tableau 1. Stratum I for even parity.

\begin{tabular}{|c|c|c|c|}
\hline & $\sigma \sigma \underline{\sigma \sigma \sigma}$ & Trough-L & Trough-R \\
\hline a. & 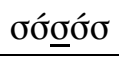 & & \\
\hline b. & 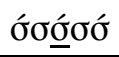 & $* ! \mathrm{W}$ & $*$ \\
\hline
\end{tabular}

Tableau 2. Stratum I for odd parity.

3.2. STRATUM II. The second stratum inherits the metrical structure assigned by the first stratum as its input. With this, it must both propel deletion in the weak positions defined by that structure, as well as reassign prominences from the right edge leftward. The second of these effects is accomplished by inverting the ranking between the trough constraints, such that TROUGH-R is re-ranked above TROUGH-L. Tableaux 3 and 4 show how this ranking functions without syncope, e.g., in forms like (8) where syncope is blocked by phonotactic constraints.

\begin{tabular}{|c|c|c|c|}
\hline & 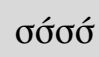 & Trough-R & Trough-L \\
\hline a. & 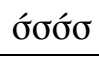 & & * \\
\hline b. & 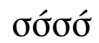 & $* ! \mathrm{W}$ & $\mathrm{L}$ \\
\hline
\end{tabular}

Tableau 3. Stratum II stress realignment for even parity (without syncope). 


\begin{tabular}{|c|c|c|c|}
\hline & 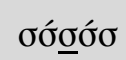 & Trough-R & Trough-L \\
\hline a. & 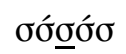 & & \\
\hline b. & 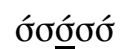 & $* ! \mathrm{W}$ & $*$ \\
\hline
\end{tabular}

Tableau 4. Stratum II stress realignment for odd parity (without syncope).

Syncope necessitates the re-ranking of $* \breve{V}$ above MAX-V. However, the targets of deletion are not motivated by surface stress, but rather the metrical structure it receives as an input from the first stratum. This entails a constraint demanding faithfulness to stressed syllables in the input, MAX-ó ("don't delete syllables which are stressed in the input"), which has the effect of protecting those syllables from deletion regardless of whether they remain stressed in the output of the second stratum. The crucial ranking to motivate syncope in the appropriate syllables is therefore MAX-ó $>>* \breve{V}>>$ MAX-V. Tableaux (5) and (6) below demonstrate this result for even and odd syllable parities.

\begin{tabular}{|c|c|c|c|c|c|c|}
\hline & $\sigma_{1} \sigma_{2} \underline{\sigma}_{3} \sigma_{4}$ & TROUGH-R & MAX-ó & $* \overline{\mathrm{V}}$ & TROUGH-L & MAX-V \\
\hline a. & $\sigma_{1} \hat{\sigma}_{2-} \sigma_{4}$ & & & $* *$ & & $*$ \\
\hline b. & $\sigma_{1} \tilde{\sigma}_{2} \underline{\sigma}_{3} \hat{\sigma}_{4}$ & $* ! \mathrm{W}$ & & $* *$ & & $\mathrm{~L}$ \\
\hline c. & $\tilde{\sigma}_{1} \sigma_{2} \underline{\sigma}_{3} \sigma_{4}$ & & & $* *$ & $* ! \mathrm{W}$ & $\mathrm{L}$ \\
\hline d. & $\sigma_{1-} \sigma_{3} \sigma_{4}$ & & $* ! \mathrm{W}$ & $* *$ & & $*$ \\
\hline
\end{tabular}

Tableau 5. Stratum II syncope and stress realignment for even parity.

\begin{tabular}{|c|c|c|c|c|c|c|}
\hline & $\sigma_{1} \sigma_{2} \underline{\sigma}_{3} \sigma_{4} \sigma_{5}$ & TROUGH-R & MAX-ó & $* \breve{\mathrm{V}}$ & TROUGH-L & MAX-V \\
\hline a. & $\hat{\sigma}_{1} \sigma_{2-} \sigma_{4} \sigma_{5}$ & & & *** & * & * \\
\hline b. & $\sigma_{1} \hat{\sigma}_{2} \underline{\sigma}_{3} \hat{\sigma}_{4} \sigma_{5}$ & & & $* * * ! \mathrm{W}$ & $\mathrm{L}$ & $\mathrm{L}$ \\
\hline c. & $\hat{\sigma}_{1} \sigma_{2} \underline{\sigma}_{3} \sigma_{4} \hat{\sigma}_{5}$ & $* ! \mathrm{W}$ & & $* *$ & * & $\mathrm{L}$ \\
\hline d. & $\hat{\sigma}_{1-} \underline{\sigma}_{3} \hat{\sigma}_{4} \sigma_{5}$ & & $* \mathrm{~W} !$ & $* *$ & * & * \\
\hline
\end{tabular}

Tableau 6. Stratum II syncope and stress realignment for odd parity.

In these tableaux, we can see that TROUGH-R successfully reverses the direction in which metrical structure is built, $* \breve{V}$ propels deletion in weak syllables, and MAX-ó prevents deletion from occurring in syllables which were stressed in the input. Tableau 6 also demonstrates another critical ranking: $* \breve{V}$, which motivates deletion by dominating MAX-V, must also dominate TROUGH-L in order to rule out candidate (b), which violates neither TROUGH constraint. The outputs of the tableaux above are the observed surface forms, with deletion as expected. A two-stratum approach is thus mechanically successful at deriving syncope.

3.3. INDEPENDENT EVIDENCE FOR STRATA. One outstanding question is whether there is other support for a stratal analysis. Do other processes in Southern Pomo suggest that a level-ordered 
derivation is necessary? The analysis outlined above appears to show both strata operating over strings that are of equal morphological complexity. How does this relate to the original formulation of SOT, in which strata correspond to morphologically-determined levels, or to a split between lexical and postlexical phonology?

Convergent evidence for strata in Southern Pomo arises from phrasal and word-internal phenomena. It has been observed in the literature that surface stress is assigned in a domain larger than the word (Walker, 2013/2020; Buckley, 2019), and phrasal stress shift provides evidence that surface stress is assigned at the level of the phrase. The examples in (10) show stress shifting rightward to avoid a lapse within a phrase, with the shifted stress underlined:

Phrasal stress shift

a. [ts'íh.ta $]_{\omega}[\text { min.ná:n.ti }]_{\omega}$

$\rightarrow$ [ts'ih.tà min.ná:n.ti $]_{\varphi}$

“trapping birds" (W 314)

b. [na:.phí.jow $]_{\omega}[\text { Pah.tgáh.tej }]_{\omega}$

$\rightarrow$ [ná:.phi.jow Pah.tfáh.tfej $]_{\varphi}$

"all human beings" (W 543)

Enclitics are also included in this larger stress domain, as seen in (11), but do not participate in some word-internal sandhi processes.

(11) Enclitics participate in surface stress

[hùw.way ${ }^{\mathrm{h}} \cdot \mathrm{k}^{\mathrm{h}} \mathrm{è.} \mathrm{th}^{\mathrm{h}} \mathrm{ot}_{n}$ '.wá?.ja]

hu(:)w-ad-k $\mathrm{k}^{\mathrm{h}}: \mathrm{e}=\mathrm{th}^{\mathrm{h}} \mathrm{ot} \mathrm{t}_{\mathrm{n}}=$ ?wa=?ja/

go-DIR-FUT-NEG=COP.EVID=1PL.AGT

"we will not come" (W 106)

These facts suggest that the second stratum is responsible for post-lexical stress. However, syncope is clearly a word-level process: the position of syncope within a word is not determined by its context within some larger phrasal unit. This is in fact consistent with the strata above. Vowel deletion is determined by the interaction of an output-oriented markedness constraint against unstressed vowels $(* \breve{V})$, but the application of this constraint is governed by the faithfulness constraints which outrank it. MAX-ó ensures that deletion occurs in positions determined by word-level metrical structure, despite that this deletion is a phrase-level process.

Multiple other processes in Southern Pomo suggest a derivation. One is a process of hiatus resolution, which feeds syncope. In contexts where two vowels are adjacent across a morpheme boundary, the second vowel does not surface, but is also not counted in the computation of syncope. This is shown below in (12):

Hiatus resolution feeds syncope
a. [?ek.khétf.tfin]
*[?èk.khe._dú.tyin]
$/ \mathrm{Pe}(:)-\mathrm{k}^{\mathrm{h}} \mathrm{e}-\underline{\mathrm{adu}} \mathrm{t} f-\mathrm{in} /$
with.body- move- DIR- SG.IMP
b. [phej.jéd.du]
*[phèj.je._dé.du]
$/ p^{\text {he }}$-j(:)e- aded- u/
look.for- DIR- PFV
"looking for" (W 146)
"move over!" (W 155)

\footnotetext{
${ }^{6}$ In this example, Walker reports Halpern's transcription, which appears to be missing a shifted secondary stress in [ná:phijow], "all." Most words in this transcription have only one stressed marked, and the location of the stress which is transcribed is suggestive of an alternating stress on the ultima.
} 
The crucial ordering of this process relative to syncope suggests that it must be completed at an earlier stage than rhythmic deletion (i.e., at the word level corresponding to the first stratum).

Similarly, some consonant clusters in the language undergo deletion of the first segment with compensatory lengthening, a process that requires a derivational approach because moraic structure must be defined before deletion can occur (Kiparsky, 2011; Samko, 2011). An example is shown in (13), which also features hiatus resolution:

Compensatory lengthening

a. [?ek.khe._dú..le]

hi- (h)k $\mathrm{k}^{\mathrm{h}} \mathrm{-}-$ adutf- le/

with.body-move-DIR-PL.IMP

"2 move away! (sitting or lying)" (W 288)

Compensatory lengthening may also counterfeed syncope: in (13), syncope appears to be blocked by a phonotactic restriction against the complex coda which would result from deletion in the third syllable. However, the coda consonant which seems to be crucial is not present on the surface. Another possible analysis might maintain that syncope is unable to target long vowels. How this is operationalized in the proposed stratal framework requires further consideration.

3.4. INTERIM SUMMARY. Thus far, I have demonstrated that the data in Southern Pomo are generable using a two-stage derivation in SOT. The first of these strata defines weak positions from the left edge, and the second stratum deletes vowels in these positions and re-assigns prominence from the right edge. Further, I have provided independent support for the idea that there are two strata in this language, corresponding to word- and phrase level processes.

There are theoretical consequences of this proposal which must be considered. As discussed in $\S 4$, a stratal analysis may "pathologically" overgenerate in undesirable ways. The question, then, is whether this syncope pattern can also be achieved in parallel, without a derivation. If a derivational analysis is truly necessary, is this pattern also possible in a more restrictive framework with a static constraint ranking, like Harmonic Serialism (HS, Prince \& Smolensky, 1993/2004; see also McCarthy, 2000)? In §4, I consider multiple such analyses.

4. The case against strata. It should be noted that a stratal analysis of metrical opacity are not without precedent, as similar proposals have been made to describe similar asymmetries between stress and (seemingly) metrically conditioned phenomena in other languages. Derivational strata have been proposed to account for vowel lengthening and stress interactions in Tübatulabal (UtoAztecan, California; Benz, 2018; similarly suggested in Heath, 1981), and stress freezing in Washo (isolate, California; Benz, 2018).

The use of strata in this account is predicated on the observation that syncope cannot be predicted from surface structure, and is thus metrically opaque. If, however, syncope can be shown to satisfy surface-oriented constraints - that is, if syncope is transparent - then a derivation is unnecessary. This may be a desirable outcome from the perspective of typological prediction: it has been observed that stratal architectures pathologically overgenerate, predicting typologically strange phenomena (e.g., Wolf, 2012). For instance, a first stratum could reduce all vowels in weak positions to schwa, and realignment of metrical structure in a subsequent stratum could then produce a language where all and only schwa is stressed:

Strata generate 'all and only schwas are stressed'

$\underset{/ \mathrm{CVCV} /}{\text { Input }} \rightarrow \frac{\text { Stratum I }}{\text { CV́.Cə }} \rightarrow \frac{\text { Stratum II }}{\text { CV.Cá }}$


Another example offered by Wolf (2012) similarly produces a language in which all and only unstressed syllables start with aspirated stops. Typologically, the distribution of both schwa (or reduced vowels more generally) and aspiration are related to prominence. Crosslinguistically, schwa occurs either in only weak syllables or all syllables, but never exclusively in strong positions. The opposite generalization holds for aspiration, which is found in either all or only strong positions, but not exclusively in weak ones.

A universal CON is meant to operationalize exactly these asymmetries, but in these examples, highly marked surface structures arise without the existence of constraints that directly promote those structures. In fact, reversals in metrical structure can produce patterns despite highly ranked markedness constraints expressly penalizing them. Insofar as theories of the grammar should be restrictive enough to rule out unattested patterns and make strong typological predictions, strata might be counterproductive. Further, the fact that these patterns are unattested might reflect the fact that opacity of this type is difficult to learn (see, for example, Nazarov \& Pater, 2017; Boersma \& van Leussen, 2017; i.a.). Given these concerns, we must ask if this pattern can be generated in parallel, or in a more restrictive derivational framework.

4.2. PARALlELIST APPROACHES. As discussed in $\S 1$, there are previous successful analyses of similar cases in the literature that rely on transparent, surface-oriented constraint interactions. These have sought to leverage constraints that promote deletion in weak positions, either to minimize the number of unparsed syllables (or syllables in general), or ensure that stress only falls on syllables containing enough phonological material (i.e. Stress-to-Weight, SWP). The former approach utilizes alignment constraints, which demand the alignment of metrical structure to a word edge.

4.2.1. Alignment. Given that surface metrical structure in Southern Pomo is aligned to the right edge of the word, one possibility to explain syncope is the ranking ALIGN-R (defined below) over MAX-V.

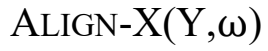

For each metrical element $Y$ (foot or prominence) in the output, assign one violation for each intervening syllable between $\mathrm{Y}$ and the $\mathrm{X}$ (right or left) word edge.

It is possible to represent this alignment constraint with respect to prominences or foot edges. In either case, deletion could satisfy alignment by virtue of simply reducing the amount of material in a word, and thus necessarily reducing the average distance between any element and the right word edge. I will first address ALIGN-R, because fixed penultimate stress and right-toleft iteration suggests that this constraint should be higher ranked than ALIGN-L. However, we find that forms with an odd number of underlying syllables are not more harmonic with respect to alignment after syncope, whether feet are trochaic or iambic. Presupposing the appropriate ranking of constraints to produce surface stress, Tableaux (7) and (8) below show that the desired winners are in fact harmonically bounded due to their violations of MAX-V:

\begin{tabular}{|c|c|c|c|}
\hline$\sigma \sigma \underline{\sigma \sigma \sigma}$ & IAMB & AligN-R(FT, $\omega)$ & MAX-V \\
\hline a. $\odot\left(\hat{\sigma}_{1}\right)\left(\sigma_{2-} \sigma_{4}\right) \sigma_{5}$ & & $* * * *$ & $* !$ \\
\hline b. $\mathscr{\gtrless}\left(\sigma_{1} \tilde{\sigma}_{2}\right)\left(\underline{\sigma}_{3} \tilde{\sigma}_{4}\right) \sigma_{5}$ & & $* * * *$ & $\mathrm{~L}$ \\
\hline
\end{tabular}

Tableau 7. Tableau 8. ALIGN-R fails to generate syncope with iambs. 


\begin{tabular}{|c|c|c|c|}
\hline$\sigma \sigma \underline{\sigma \sigma \sigma}$ & TROCHEE & ALIGN-R(FT, $\omega)$ & MAX-V \\
\hline a. $:\left(\sigma_{1} \sigma_{2}\right)_{-}\left(\sigma_{4} \sigma_{5}\right)$ & & $* *$ & *! \\
\hline b. $\stackrel{\sigma_{1}}{\otimes}\left(\hat{\sigma}_{2} \underline{\sigma}_{3}\right)\left(\sigma_{4} \sigma_{5}\right)$ & & ** & $\mathrm{L}$ \\
\hline
\end{tabular}

Tableau 8. ALIGN-R fails to generate syncope with trochees.

ALIGN-R is also unsuccessful when calculating distance from prominences to the right edge, which has the same violation profile as iambs. In this case, though, alignment will fail in evenparity forms as well, even though the attested winner is more harmonic than the faithful candidate without deletion. Because alignment is insensitive to the location of syncope, deletion in any syllable will yield an equally harmonic competitor, and worse yet, this promotes pathological deletion of as many syllables as possible (to the extent allowed by phonotactics). This is shown in Tableau (9):

\begin{tabular}{|c|c|c|c|}
\hline & $\sigma_{1} \sigma_{2} \sigma_{3} \sigma_{4} \sigma_{5}$ & $\operatorname{ALIGN-R(\sigma ,\omega )}$ & MAX-V \\
\hline a. : & $\sigma_{1} \sigma_{2-} \sigma_{4} \sigma_{5}$ & $* * * *$ & * \\
\hline b. & $\sigma_{1-} \sigma_{3} \sigma_{4} \sigma_{5}$ & $* * * *$ & * \\
\hline d. $\stackrel{*}{*}$ & $\sigma_{1-} \sigma_{3-} \sigma_{5}$ & $*_{\mathrm{L}}$ & $* * \mathrm{~W}$ \\
\hline
\end{tabular}

Tableau 9. ALIGN-R fails to choose between candidates.

ALIGN-R cannot adjudicate between the desired candidate (a) and competitors which have the same violation profile (b), but militates for candidates like (c) which delete as much material as possible. The constraint fails to predict the location of syncope and sufficiently restrain deletion.

The same holds for ALIGN-L. Because surface stress is penultimate, any prominence is always at least one syllable from the right edge, and for this reason ALIGN-LEFT fairs better than ALIGN-R in picking out the desired outputs relative to their faithful competitors. However, it too underdetermines the output. Deletion anywhere results in the same harmonic improvement, and so syncope cannot be generated in the correct location. Given the failure of these constraints to pick out the correct targets for syncope, we must look elsewhere for a parallel analysis.

4.2.2. StRESS-TO-WEIGHT. Syncope appears to always result in fewer stressed light syllables, due to the phonotactic restrictions of the language and the fact that initial syllables in the language are always heavy due to the 'laryngeal increment' (see footnote 3). SWP, which assigns violations to stressed light syllables, is thus a plausible constraint to motivate syncope, and maximally well-formed words will avoid light stressed syllables. Impressionistically, this appears to reflect the data. Syncope is blocked in closed syllables by phonotactic constraints, and so words which have undergone syncope invariably have one less light syllable. The resulting heavy syllable is frequently stressed. Indeed, as Tableau 10 and 11 show, the syncopated candidates are more harmonic than their faithful competitors:

\begin{tabular}{|ll|c|c|}
\hline & $\sigma_{\mathrm{H}} \cdot \mathrm{CV}_{2} \cdot \mathrm{CV}_{3} \cdot \sigma$ & SWP & MAX-V \\
\hline a. & $\sigma_{\mathrm{H}} \cdot \mathrm{CV}{ }_{2} \mathrm{C} \_\cdot \sigma$ & & $*$ \\
\hline b. & $\sigma_{\mathrm{H}} \cdot \mathrm{CV}{ }_{2} \cdot \mathrm{CV} \cdot \sigma$ & $* ! \mathrm{W}$ & $\mathrm{L}$ \\
\hline
\end{tabular}

Tableau 10. Syncope increases harmony for SWP (even-parity). 


\begin{tabular}{||cc|c|c||}
\hline & $\sigma_{\mathrm{H}} \cdot \mathrm{CV}_{2} \cdot \mathrm{CV}_{3} \cdot \mathrm{CV}_{4} \cdot \sigma$ & $\mathrm{SWP}$ & $\mathrm{MAX}-\mathrm{V}$ \\
\hline a. & $\sigma_{\mathrm{H}} \cdot \mathrm{CV}_{2} \mathrm{C} \cdot \mathrm{CV}_{4} \cdot \sigma$ & $*$ & $* *$ \\
\hline b. & $\sigma_{\mathrm{H}} \cdot \mathrm{CV}_{2} \cdot \mathrm{CV}_{3} \cdot \mathrm{CV}_{4} \cdot \sigma$ & $* * ! \mathrm{W}$ & $\mathrm{L}$ \\
\hline
\end{tabular}

Tableau 11. Syncope increases harmony for SWP (odd-parity).

Forms that have undergone syncope are more harmonic for SWP than candidates without deletion. As previously mentioned, this is typically because deletion shifts stress leftward, and in words with an odd parity of underlying syllables, this results in the heavy initial syllable receiving a secondary stress. The resulting wellformedness is not necessarily local, as can be seen in (16), where the derived heavy syllable is not stressed:

Syncope increases global SWP harmony

a. /Rah.tǹ.mo.kó.tyin/ (2 SWP violations) $\rightarrow$ [ Pàh.tim_.kó.tgin] (1 SWP violation)

b. / Rah.k à.bu..tá.ka/ (2 SWP violations) $\rightarrow$ [ ?àh.k ${ }^{\mathrm{h}}$ ap_.tá.ka] (1 SWP violation)

Here, main stress remains on a light syllable, and the heavy syllable formed by vowel deletion is itself unstressed. The word, however, is globally more harmonic with respect to SWP, because stress is shifted leftward onto the heavy initial syllable. Syncope doesn't result in a heavy stressed syllable locally, but there is one fewer light stressed syllable. This is an example of how parallelist approaches to syncope have generally resolved apparent opacity: a process may seem unmotivated or opaque locally, but results in a more harmonic form under global evaluation (Gouskova, 2003; Blumenfeld, 2006).

Given the apparent success of this approach, can we conclude that syncope is transparent? No: like the alignment constraints, SWP is unable to correctly predict the location of syncope. As shown in Tableaux (12) below, deletion in the fourth syllable, rather than the third, would result in a maximally harmonic candidate for SWP:

\begin{tabular}{|c|c|c|}
\hline$\sigma_{\mathrm{H}} \cdot \mathrm{CV}_{2} \cdot \mathrm{CV}_{3} \cdot \mathrm{CV}_{4} \cdot \sigma$ & SWP & MAX-V \\
\hline a. $\odot \sigma_{\mathrm{H}} \cdot \mathrm{CV}_{2} \mathrm{C}$-_C $_{-} \mathrm{CV}_{4} \cdot \sigma$ & $*$ & $* *$ \\
\hline$\sigma_{\mathrm{H}} \cdot \mathrm{CV}_{2} \cdot \mathrm{CV}_{3} \cdot \mathrm{CV}_{4} \cdot \sigma$ & $* * ! \mathrm{W}$ & $\mathrm{L}$ \\
\hline c. $\stackrel{\sigma_{\mathrm{H}}}{ } \cdot \mathrm{CV}_{2} \mathrm{C}_{\underline{V}_{3}} \mathrm{C} . . . \sigma$ & $\mathrm{L}$ & $*$ \\
\hline
\end{tabular}

Tableau 12. SWP predicts the incorrect location for syncope.

The attested form is harmonically bounded by the competitor without light stressed syllables. Notably, these are the same type of candidate which alignment constraints were similarly unable to rule against: those with different sites of deletion. Using SWP, an alternative target of deletion is incorrectly predicted for any word of odd syllable parity where the penult (which will surface with stress) is light. The optimal location for deletion is the penult itself, but syncope instead targets the third and fifth syllables of the word, and this penult is preserved.

These surface-oriented constraints - those that militate for stress to fall on certain types of syllables, and those that militate for reducing phonological material - cannot generate the observed pattern in parallel OT precisely because there is no reference to positions defined within the metrical structure. In contrast, syncope in the stratal account is conditioned by the existence of metrically weak positions. Alongside this, the derivation must allow re-ranking of 
the constraints responsible for the direction of stress assignment.

For this reason, accounts based on a singular ranking - whether utilizing output-output faithfulness (e.g., Transderivational Faithfulness, or TF; Benua, 2000), or a stepwise constraint satisfaction, like HS or OT with Candidate Chains (OT-CC, McCarthy, 2006) - are not tenable. TF was devised to handle opacity of a type arising from morphological inheritance, which is of no use in the present case. Meanwhile, in HS and OT-CC architectures, opacity is allowed to arise from the gradualness condition - that is, through satisfying constraints sequentially, from highest- to lowest-ranked, rather than in parallel. This, however, does not allow those highly ranked constraints to be violated in later stages of the derivation. Metrical structure, which in an HS or OT-CC account would be motivated by highly ranked constraints, is thus not possible to simply undo and reverse (McCarthy, 2008; Pruitt, 2010; Elfner, 2016). These factors militate for an account in Stratal OT (SOT; Kiparsky, 2001), with free re-ranking of constraints between strata.

4.3. Disjoint FOOTING. As discussed in $\$ 2.3$, derivational frameworks which depend on a single ranking are not able to reverse the direction of stress assignment. Once a metrical structure is built, it cannot be undone. However, these frameworks may be able to generate the attested pattern using disjoint footing. Under this type of analysis, there are two tiers of distinct metrical structure that coexist within a word, each conditioning the application of one of the two rhythmic phenomena in question. A schematization of this is shown in (17):

$$
\begin{aligned}
& \text { Disjoint footing for stress and syncope } \\
& \text { Stress } \quad \mathrm{R} \rightarrow \mathrm{L} \quad \sigma\left(\begin{array}{lll}
\sigma^{\prime} & \sigma
\end{array}\right)\left(\begin{array}{lll}
\sigma^{\sigma} & \sigma
\end{array}\right) \\
& \text { Deletion } \mathrm{L} \rightarrow \mathrm{R} \quad\{\underline{\sigma} \sigma\}\{\underline{\sigma} \sigma\} \sigma
\end{aligned}
$$

Mechanically, this may be quite similar to the stratal proposal above: a left-to-right structure determines the locations of syncope, and a right-to-left structure assigns surface prominence. These structures could then be motivated by distinct sets of process-specific metrical constraints. Because surface stress is calculated based on the syllable string after syncope, this must still be done derivationally. This readily produces the same set of typologically strange rhythmic processes predicted by SOT. Versions of disjoint footing have been proposed for similar phenomena, such as the aforementioned interaction of vowel lengthening and stress in Tübatulabal (Heath, 1981; Aion, 2003; cf. Benz, 2018), and alternating epenthesis and stress in Huariapano (González, 2007; Parker, 1998a; cf. Bennett, 2013).

I reject such an account on three grounds. First: previous literature utilizing disjoint footing has not provided a concrete, falsifiable theory. Because these metrical structures are processspecific, they are not independently motivated within the languages for which they have been proposed, and there are no specific theorized restrictions on what processes they can condition. Secondly, stress fundamentally represents hierarchical relationships between prosodic elements. It may be reflected in segmental processes like deletion or epenthesis, but these processes are not themselves relational in the same way. For this reason, the notion of competing hierarchies within words is not desirable. Finally, disjoint footing is unable to account for non-rhythmic effects, such as compensatory lengthening and the feeding relationship between hiatus resolution and syncope. Moreover, it is not clear how such an analysis would be able to accurately account for phrasal stress shift, a rhythmic phenomenon in a domain larger than the word. While this analysis may be mechanically similar to one in SOT for the purpose of deriving syncope, it is process-specific, limited to syncope alone. If we concede that overgenerating systems are necessary to account for some types of opacity, it is more parsimonious to choose the system 
which offers the greatest empirical coverage.

5. Discussion and conclusion. In this paper, I have shown that Southern Pomo demonstrates a pattern of rhythmic vowel deletion which is not predictable from the surface metrical structure. Syncope and stress assignment seem to be evaluated over different rhythmic structures, with syncope aligned with the left edge, and stress with the right edge. Syncope thus appears to occur in concert with a realignment of metrical structure, rendering it opaque. This poses a significant problem for both parallelist and non-stratal derivational frameworks. I analyze this pattern in a SOT framework involving two strata. The first of these strata defines the weak positions targeted for deletion, while the second stratum enacts both deletion and re-assignment of prominence. Independent evidence for the proposed strata is found in phrasal stress shift, suggesting that surface stress is assigned in a domain larger than the word. While stratal architectures have been criticized for typological overgeneration, this work suggests that such overgeneration is necessary to analyze metrical opacity.

A historical explanation may further justify this analysis. Stress in other Pomo languages is left-aligned, and Buckley (2019) analyzes Proto-Pomo metrical structure as trochaic with initialsyllable extrametricality - mechanically identical to the output determined in first stratum by TROUGH-L. Further, Buckley proposes that prominence in Southern Pomo reflects contactinduced change due to intermarriage and bilingualism with the Bodega variety of Coast Miwok (Miwokan; California) a language with overwhelmingly penultimate stress (89\%; Buckley, 2019; Callaghan, 1970) Thus it could be that Miwok-dominant child or adult learners of Southern Pomo may have imposed this prevailing pattern of metrical organization from Miwok at the phrasal level. The metrical reversal in the second stratum then represents a contact-propelled shift. Strata may thus not only be necessary for cases of metrical opacity, but could also represent historical change (Bermúdez-Otero 2015; Kiparsky 2015; Gordon, 2016).

Such systems pose a learnability problem. What evidence does the learner have for opacity, versus a transparent analysis? Some work has suggested that opaque patterns of this sort prompt restructuring by learners, who acquire a different constraint ranking to transparently account for opaque input (e.g., Hayes, 1999). There is some suggestive evidence that Southern Pomo was in the midst of such a restructuring, in the form of exceptional syncope in the fourth syllable of some words, as in (18) below. The attested forms are given, along with the expected forms that do not appear:

$$
\begin{aligned}
& \text { (a) [hàt.ta.lók._ty'in] } \\
& \text { *[hàt.tal._kó.ty'in] } \\
& \text { /hat:-alokoty-in/ } \\
& \text { move.foot-DIR-SG.IMP } \\
& \text { "[move foot] up out of[!]" (W 280) }
\end{aligned}
$$

$$
\begin{aligned}
& \text { [bè:.ne.m } \mathrm{m}^{\mathrm{h}} \mathbf{u ́}^{\mathrm{h}} \cdot . . \text { le] } \\
& \text { *[bè'.nem }{ }^{\mathrm{h}} \text {...thú.le] } \\
& \text { /be:-ne-m }{ }^{\text {h }} \text { ut ' '-th } u-l e / \\
& \text { with.arms-grasp-RECIP-PROH-PL.IMP } \\
& \text { "2 don't hug each other!" (W 299) }
\end{aligned}
$$

These forms have no light stressed syllables, and are thus transparent for SWP, suggesting a "flattened" re-analysis of the grammar. Whether this truly represents restructuring, and whether a restructured grammar would require a derivational framework are questions that require further investigation.

\section{References}

Aion, Nora. 2003. Selected topics in Nootka and Tübatulabal phonology. New York, NY: City University of New York dissertation.

Bennett, Ryan. 2013. The uniqueness of metrical structure: Rhythmic phonotactics in 
Huariapano. Phonology 30(3). 355-398. https://doi.org/10.1017/S0952675713000195.

Bennett, Ryan. 2013. A re-evaluation of 'disjoint' footing. Handout presented at Yale University, New Haven, NH.

Benua, Laura. 1997. Transderivational identity: Phonological relations between words. Amherst, MA: University of Massachusetts Amherst dissertation.

Bermúdez-Otero, Ricardo. 2011. Cyclicity. In Marc van Oostendorp, Colin J. Ewen, Elizabeth Hume \& Keren Rice (eds.), The Blackwell companion to phonology. 2019-2048. Hoboken, NJ: Wiley-Blackwell.

Bermúdez-Otero, Ricardo. 2015. Amphichronic explanation and the life cycle of phonological processes. In Patrick Honeybone \& Joseph Salmons, (eds.) The Oxford handbook of historical phonology. 374-399. Oxford, UK: Oxford University Press.

Blumenfeld, Lev A. 2006. Constraints on phonological interactions. Palo Alto, CA: Stanford University dissertation.

Boersma, Paul \& Jan-Willem van Leussen. 2017. Efficient evaluation and learning in multilevel parallel constraint grammars. Linguistic Inquiry 48(3). 349-388. https://doi.org/10.1162/ling_a_00247.

Buckley, Eugene. 1992. Kashaya laryngeal increments, contour segments, and the moraic tier. Linguistic Inquiry 23(3). 487-496.

Buckley, Eugene. 2019. Change and contact in Pomoan stress patterns. Group in American Indian Languages (GAIL), UC Berkeley. May 2019.

Callaghan, Catherine. 1970. Bodega Miwok Dictionary. Berkeley, CA: University of California Press.

Elfner, Emily. 2016. Stress-epenthesis interactions in Harmonic Serialism. In John J. McCarthy \& Joe Pater (eds.), Harmonic grammar and harmonic serialism. 261-300. Sheffield, UK: Equinox.

González, Carolina. 2007. Typological evidence for the separation between stress and foot structure. In Matti Miestamo \& Bernhard Wälchli (eds.), New challenges in typology: Broadening the horizons and redefining the foundations. 55-75. Berlin: Mouton de Gruyter.

Gordon, Matthew. 2002. A factorial typology of quantity-insensitive stress. Natural Language \& Linguistic Theory 20. 491-552. https://doi.org/10.1023/A:1015810531699.

Gordon, Matthew. 2016. Metrical incoherence: Diachronic sources and synchronic analysis. In Jeffrey Heinz, Rob Goedemans \& Harry van der Hulst (eds.), Dimensions of phonological stress. 9-48. Cambridge, UK: Cambridge University Press.

Gouskova, Maria. 2003. Deriving economy: Syncope in Optimality Theory. Amherst, MA: University of Massachusetts Amherst dissertation.

Halpern, Abraham. 1984. Southern Pomo h and $\mathrm{P}$ and their reflexes. Journal of California and Great Basin Anthropology 3-43.

Hayes, Bruce. 1999. Phonological restructuring in Yidin and its theoretical consequences. In Ben Hermans \& Marc van Oostendorp (eds.), The derivational residue in phonological optimality theory. 175-205. Amsterdam, NL: John Benjamins.

Heath, Jeffrey. 1981. Tübatulabal phonology. Harvard Studies in Phonology 2. 188-217.

Kager, Rene. 1997. Rhythmic vowel deletion in Optimality Theory. In Iggy Rocca (ed.), Derivations and constraints in phonology. 463-499. Oxford, UK: Oxford University Press.

Kiparsky, Paul. 2000. Opacity and cyclicity. The Linguistic Review 17. 351-365. 
https://doi.org/10.1515/tlir.2000.17.2-4.351.

Kiparsky, Paul. 2011. Compensatory lengthening. In Charles E. Cairns \& Eric Raimy (eds.), Handbook of the syllable. 33-69. Leiden, NL: Brill.

Kiparsky, Paul. 2015. Phonologization. In Patrick Honeybone \& Joseph Salmons, (eds.), The Oxford handbook of historical phonology. 563-579. Oxford, UK: Oxford University Press.

McCarthy, John J. 2008. The serial interaction of stress and syncope. Natural Language \& Linguistic Theory 26. 499-546. https://doi.org/10.1007/s11049-008-9051-3.

McCarthy, John J. 2000. Harmonic Serialism and parallelism. North East Linguistics Society (NELS) 30. 501-524.

McCarthy, John J. 2006. Hidden generalizations: Phonological opacity in Optimality Theory. Sheffield, UK: Equinox.

McLendon, Sally. 1973. Proto Pomo. Berkeley, CA: University of California Press.

Nazarov, Aleksai \& Joe Pater. 2017. Learning opacity in stratal maximum entropy grammar. Phonology 34(2). 299-324. https://doi.org/10.1017/S095267571700015X.

Oswalt, Robert L. 1998. Three laryngeal increments of Kashaya. In Leanne Hinton \& Pamela Munro (eds.), Studies in American Indian languages: Description and theory. 87-94. Berkeley, CA: University of California Press.

Oswalt, Robert L. 1976. Comparative verb morphology of Pomo. California Indian Library Collections Project.

Parker, Steve. 1998. Disjoint metrical tiers and positional markedness in Huariapano (Panobo). Amherst, MA: University of Massachusetts, Amherst MS thesis.

Prince, Alan, \& Paul Smolensky. 1993. Optimality Theory: Constraint interaction in generative grammar. Hoboken, NJ: Wiley \& Sons.

Prince, Alan. 1990. Quantitative consequences of rhythmic organization. Chicago Linguistic Society (CLS) 26(2).

Prince, Alan. 1983. Relating to the grid. Linguistic inquiry 14(1). 19-100.

Samko, Bern. 2011. Compensatory lengthening in Harmonic Serialism. Santa Cruz, CA: University of California, Santa Cruz qualifying paper.

Walker, Neil Alexander. 2013. A grammar of Southern Pomo, an Indigenous language of California. Santa Barbara, CA: University of California, Santa Barbara dissertation. Later published as Walker. 2020. A grammar of Southern Pomo. Lincoln, NE: University of Nebraska Press.

Wolf, Matthew. 2012. Inversion of stress-conditioned phonology in Stratal OT. New Haven, CT: Yale University MS thesis. 